\title{
An Empirical Study on Momentum Effect and Reversal Effect of Growth Enterprises Market
}

\author{
Meng Ai \\ School of Economics ,Shanghai University; P.R.China \\ carrieyong@126.com
}

Keywords: Momentum effect; Reversal effect; Growth enterprises market

\begin{abstract}
Momentum effect and reversal effect are the financial visions confirmed by many scholars at home and abroad. However, due to the different market conditions in different countries, the conclusions drawn from different market data are also different. This paper analyzes the weekly data of 364 GEM stocks from January 1, 2015 to December 21, 2015 by constructing the combination of winner portfolio and loser portfolio, and discusses the short-term momentum effect and the short-term reversal effect. The other conclusion we got is that with the holding time gradually increased, the reversal effect will gradually decline. In addition, we also analyze the possible factors of the abnormal results exist of the empirical study.
\end{abstract}

\section{Introduction}

Fama put forward an effective market hypothesis that in a fully effective market, because the stock reflects all the relevant information, so investors cannot be expected to obtain excess returns, but the market has a lot of contradictions with the theory, called the capital market is different Like the momentum effect and the reversal effect is this kind of typical market vision. Many researchers at home and abroad have analyzed the momentum effect and reversal effect in the market environment.

However, due to the difference of the market situation and the way of selecting the data, the empirical results are different. The domestic research is carried out from the A-share market Analysis, but for the change in the case of more GEM whether there is this phenomenon, there are few domestic scholars to analyze. The GEM has been set up since October 30, 2009, and there may be a lot of problems for small and medium-sized businesses, which also makes the investment risk of the GEM very high. Therefore, we use the GEM stock as the object of its analysis. Hoping to make a remedy for the research area of the GEM market based on the analysis of empirical data.

\section{Literature Review}

Eugene Fama proposed an effective market hypothesis theory (EMH) in 1970. Here we only analyze the weak effective hypothesis. However, in the actual market operation, we find that there are many stock market visions that violate the market validity hypothesis, and the momentum effect and the reversal effect of the stock price are one of them.

For Chinese stock market, many experts and scholars were also analyzed and studied on this issue. Due to the characteristics of the Chinese stock market, the significant effect of the momentum effect and the reverse effect will be different under the different circumstance like the different length of the period, the different market situation, the variable industry and the size of the company. Xie Linmin (2014) analyzed the analysis of the whole week data from Jan. 1, 2006 to January 1, 2014, based on the analysis of the division of industry index based on SWS, and concluded that, taking into account the transaction cost, Combination "and industry" loser combination "momentum strategy to deal, excess returns can be significantly improved. Song Xiwei, Gu Jiayin (2016) pointed out that within three 
months the market tends to show a significant reversal effect, and more than three months, this will show momentum effect.

In addition, for the source of the momentum effect and the influencing factors, many experts and scholars have also carried out related research. Yasser Alhenawi (2015) pointed out that the growth rate of enterprises and the size of enterprises will have a positive impact on the momentum effect. Wang Jing (2015) that the market factors and psychological changes due to investors is the main reason for the impact of momentum. Shi Yongdong and Wang Zhen (2015) through the analysis of the A shares of the card, pointed out that the momentum effect is significant and the investor's emotions have a certain degree of correlation.

\section{Data Selection and Model Construction}

Research methods. For the study of momentum effects and reversal effects, the mainstream approach is to use Jegadeesh and Titman's approach to build winners' combinations and loser combinations based on stock's past performance. The momentum strategy is to buy the winner combination, sell the loser combination, and reverse the strategy to buy the loser combination, sell the winner combination. However, due to the preparation of the program code is too complex, this paper to take a random sampling of the data processing analysis

Data processing. The data used in this article is from the CSMAR database to select the weekly closing price of the previous stock from January 1, 2015 to December 31, 2015.

Sample selection. Based on the GEM stock and taking into account the special effects of some other factors on the stock yield, the sample stock is screened according to the following criteria.1) IPO will lead to a sharp rise in its stock prices, so this article choose to market time is greater than 3 months into the sample.2) No trading for four consecutive weeks is not included.3)Suspended shares are not included in the sample analysis.Based on the above three aspects, the sample selection of this article 364 listed companies to analyze the data.In order to reduce the complexity of data processing, in the overall sample, random sampling of the way to select 100 of them to analyze the stock. While choosing the GEM index reflects the same period of market standards.

Analytical method. We will cut the sample data to analyze the weekly yield, we will form the period J defined as 1,2,4 weeks, holding period $\mathrm{K}$ set to 1,2,4 weeks, we can get nine groups of strategy performance.

the combination of winners and losers. In the formation period $\mathrm{J}$, calculate the cumulative yield of individual stocks:

$$
r_{n}=\prod_{j=1}^{J}\left(1+r_{\mathrm{n}, \mathrm{j}}\right)-1
$$

According to the calculated cumulative yield of the formation period, the stocks are sorted, select the highest yield of $5 \%$ of the stock composition of the winner combination, the lowest yield of $5 \%$ of the composition of the composition of the combination of losers. Different combinations of winners and losers are analyzed with different lengths of formation period and time interval of formation.

After determining the winners and losers portfolio, assuming that there is a short selling mechanism in the market, we use the momentum strategy to buy the winner portfolio to sell the loser portfolio. According to the method of Jegadeesh, we will carry out the investment strategy in $\mathrm{J}+1$ week to calculate the excess accumulated rate of return during the holding period. Here we use the market rate of return as a reflection of the overall performance of the same period .

Excess cumulative rate of return for winners:

$$
r_{\mathrm{n}, \mathrm{t}+\mathrm{k}}^{W}=\frac{1}{N} \sum_{n=1}^{N}\left[\prod_{k=1}^{K}\left(r_{n, t+k}^{u}+1\right)-1\right]-\tilde{r}
$$


Excess cumulative rate of return on losers:

$$
r_{\mathrm{n}, \mathrm{t}+\mathrm{k}}^{L}=\frac{1}{N} \sum_{n=1}^{N}\left[\prod_{k=1}^{K}\left(r_{n, t+k}^{d}+1\right)-1\right]-\tilde{r}
$$

Zero Cost (W-L) Excess Cumulative Yield:

$$
\mathrm{R}=r_{n, t+K}^{W}-r_{n, t+K}^{L}
$$

Since we construct winners and losers in different time intervals, we will receive different excess returns. The mean of the excess rate of return is obtained, and the average of the rate of return is obtained. In this paper, we have selected 10 sets of time intervals for different formation and duration combinations to obtain the yield level of the momentum strategy.

The average cumulative excess return on the winner portfolio:

$$
\overline{r_{W}}=\frac{1}{S} \sum_{S=1}^{S} r_{n, t+K}^{W}
$$

Average excess return on losers:

$$
\overline{r_{L}}=\frac{1}{S} \sum_{s=1}^{S} r_{n, t+K}^{L}
$$

The average excess return on the zero cost portfolio (W-L):

$$
\bar{R}=\overline{r_{W}}-\overline{r_{L}}
$$

Statistical test. For the calculated excess cumulative yield series, the eviews8.0 software was used for the simple hypothesis test to obtain the corresponding t statistic to determine the significance of the empirical test.

\section{Empirical Results and Analysis}

The empirical result of the formation period $\mathbf{J}=\mathbf{1}$. As shown in Table 1 , when the formation period is 1 week holding period is also 1 week, indicating that in a very short period the GEM stock price reflects the momentum effect. And when the formation period is one week, the holding period is two weeks or four weeks, the loser portfolio excess rate of return is greater than zero, and the winner combination of excess returns is negative, the winner combination performance if the performance of the loser combination, and t statistics $10 \%$ Level significantly shows the reversal effect. In summary, GEM stocks in a very short period of time to show a significant momentum effect, and in the short term reflects the reversal effect.

Table 1 the empirical results of the different holding period combinations for one week

\begin{tabular}{|c|c|c|c|}
\hline $\begin{array}{c}\text { Hold } \\
\text { period }\end{array}$ & $\begin{array}{c}\text { Winner portfolio average excess } \\
\text { rate of return }\end{array}$ & $\begin{array}{c}\text { Loser portfolio average } \\
\text { excess rate of return }\end{array}$ & $\begin{array}{c}\text { Zero cost arbitrage portfolio } \\
\text { average excess return }\end{array}$ \\
\hline 1 & 0.002325 & -0.011945 & 0.00962 \\
$(-0.722)$ & $(4.085) *$ \\
\hline 2 & $(1.173)$ & 0.07379 & -0.1028 \\
& -0.02906 & $(0.854) * *$ & $(-1.982) *$ \\
\hline 4 & $(-1.786) *$ & -0.04196 & -0.10754 \\
& -0.1495 & $(-1.253)^{* *}$ & $(-1.093)^{* *}$ \\
\hline
\end{tabular}

Note: $*$ indicates statistically significant at $10 \%$ critical level, $* *$ indicates statistically significant at $25 \%$ level. 
The empirical results of $\mathbf{J}=\mathbf{2}$. As shown in Table 2, the performance of the loser combination is stronger than the winner in the formation period of two weeks and the holding period is one week, but the reversal effect is not significant at the $10 \%$ level and significant at the $25 \%$ Turn effect. In the twoweek period, the yield of the winner combination is significantly weaker than the loser portfolio. And when the holding period is four weeks, it can be manifested at the $25 \%$ confidence level Reversal effect. This shows that in the formation of two weeks under several conditions, although the significance level is different, but to a certain extent, shows the GEM stocks in this period of time there is a reversal effect.

Table 2 the empirical results of the different holding period combinations for two week

\begin{tabular}{|c|c|c|c|}
\hline $\begin{array}{c}\text { Hold } \\
\text { period }\end{array}$ & $\begin{array}{c}\text { Winner portfolio average } \\
\text { excess rate of return }\end{array}$ & $\begin{array}{c}\text { Loser portfolio average } \\
\text { excess rate of return }\end{array}$ & $\begin{array}{c}\text { Zero cost arbitrage portfolio } \\
\text { average excess return }\end{array}$ \\
\hline 1 & 0.01601 & 0.1138 & -0.09780 \\
& $(0.544)$ & $(1.032)$ & $(-1.267) * *$ \\
\hline 2 & -0.04159 & 0.06768 & -0.1093 \\
& $(-1.675)^{*}$ & $(1.0861)$ & $-1.8732)^{*}$ \\
\hline 4 & -0.05979 & -0.00174 & $(-0.9659) * *$ \\
\hline
\end{tabular}

Note: $*$ indicates statistically significant at $10 \%$ critical level, $* *$ indicates statistically significant at $25 \%$ level.

The empirical results of $\mathbf{J}=\mathbf{4}$. As shown in Table 3, when the formation period is four weeks, when the holding period is one week, the average excess return of the winner combination is weaker than the loser combination, and the overall performance still presents a reversal effect. But the significance level is relatively low. And the average excess return rate of the winner combination is obviously stronger than that of the loser combination in the period of holding for one week, showing a more significant momentum effect. And when the holding period is four weeks, the average excess return of the winner combination and the loser is close to zero, but there is no significant momentum from the t statistic Effect or reversal effect.

Table 3 the empirical results of the different holding period combinations for four week

\begin{tabular}{|c|c|c|c|}
\hline $\begin{array}{c}\text { Hold } \\
\text { period }\end{array}$ & $\begin{array}{c}\text { Winner portfolio average } \\
\text { excess rate of return }\end{array}$ & $\begin{array}{c}\text { Loser portfolio average } \\
\text { excess rate of return }\end{array}$ & $\begin{array}{c}\text { Zero cost arbitrage portfolio } \\
\text { average excess return }\end{array}$ \\
\hline 1 & -0.053231 & -0.01986 & -0.0333645 \\
$(-0.4634)$ & $(0.3698)$ & $(-0.7923)^{* *}$ \\
\hline 2 & -0.07363 & -0.10722 & 0.03359 \\
& $(0.5054)$ & $(-1.6021) *$ & $(1.3327) * *$ \\
\hline 4 & 0.009411 & -0.000482 & 0.014231 \\
& $(0.0595)$ & $(-0.06753)$ & $(0.1321)$ \\
\hline
\end{tabular}

Note: $*$ indicates statistically significant at $10 \%$ critical level, $* *$ indicates statistically significant at $25 \%$ level.

\section{Conclusion}

This paper analyzes the weekly yield of Chinese GEM stocks from January 1, 2015 to December 31, 2016, and examines whether there are momentum effects and reversal effects on GEM stocks under different formation and holding periods. The main conclusions are as follows: 
1) There is a significant momentum effect on the GEM in the very short term. 2) In the short term, the GEM stocks generally showed a more significant reversal effect. And a significant level was higher than the formation period of 1 week and a holding period of 2 weeks or a formation period of 2 weeks anda holding period of 2 weeks. This is consistent with many of the past analysis results. 3) With the formation and holding period gradually increase, the significant level of short-term reversal effect is also declining.

\section{References}

[1] Jegadeesh N., S.Titman. "Returns to Buying Winners and Selling losers:Implications for Stock Market Efficiencyt".Journal of Finance,1993,(31).

[2] Yasser Alhenawi. "On the Interaction between Momentum Effect and Size Effect" .ELSEVIER, 2015, (26).

[3] Shi Yongdong, Song Xiwei, Gu Jiayin. "Enterprise investment, stock profit term structure and momentum investment strategy - empirical evidence based on Chinese stock market" . Securities Market Herald, 2016, (08): 40-48.

[4] Shi Yongdong, Wang Zhen. "Investor sentiment affect the momentum effect? - Empirical evidence from SSE A shares". Investment Research, 2015, (09): 90-103.

[5] Wang Jing. "Analysis of the source of income effects of momentum" . China Management Information, 2015, (07): 132-136.

[6] Xie Linmin. "China A-share market momentum momentum empirical study" . Fudan University, 2014. 